Archives

3| 1989

Varia

\title{
Thèses soutenues en 1988
}

\section{OpenEdition}

Journals

Édition électronique

URL : http://journals.openedition.org/ccrh/2938

DOI : $10.4000 /$ ccrh.2938

ISSN : $1760-7906$

Éditeur

Centre de recherches historiques - EHESS

Édition imprimée

Date de publication : 15 avril 1989

ISSN : 0990-9141

Référence électronique

"Thèses soutenues en 1988 ", Les Cahiers du Centre de Recherches Historiques [En ligne], 3| 1989, mis en ligne le 13 avril 2009, consulté le 21 avril 2019. URL : http://journals.openedition.org/ccrh/2938 ;

DOI : 10.4000/ccrh.2938

Ce document a été généré automatiquement le 21 avril 2019

Article L.111-1 du Code de la propriété intellectuelle. 


\section{Thèses soutenues en 1988}

\section{Doctorats de 3ème cycle}

1 Marie-Claire BEIS-GASNAULT : Pour vingt setiers de grain. Les enquêtes du procès pour la dîme de Sepeaux en 1494. (Directeur : J. LE GOFF).

2 Franca DORIGUZZI : Pratiques de prime éducation et attitutes envers l'enfant au Piémont au $\mathrm{XVIII}^{\mathrm{e}}$ siècle. La première enfance du marquis Ambrosio Ghilini. (Directeur: A. BURGUIERE).

3 Abdelkrim GABOUS : L'inconothèque maghrébine (image de l'histoire, histoire de l'image au Maghreb). Le cas de la Tunisie. Approche documentaire et archivistique de l'utilisation de l'image dans l'étude de l'histoire et de l'anthropologie du Maghreb. (Directeur : L. VALENSI).

4 Jacques HIRZY : Le père Isidro de la Asuncion, visiteur de la province carmélitaine de Nouvelle-Espagne et son « Itinerario a Indias » (1673-1679). Édition critique et traduction. (Directeur : J. P. BERTHE).

5 Bertrand de MARTIN de VIVIES : Saint Stapin en Languedoc. Autour d'un saint mythique, réalité du recours thérapeutique et cohésion sociale. (Directeur : A. DUPRONT).

6 Bernard NICOLAS : Jean XXII, l'installation du siège apostolique à Avignon. (Une politique d'investissements immobiliers et ses conséquences matérielles). (Directeur: 0. CHAPELOT).

7 Georges RICHARD : La nouvelle École de Paris et la revue «Art d'aujourd'hui » ou les abstractions au début des années cinquante. (Directeur : H. DAMISH).

\section{Doctorats E.H.E.S.S.}

8 Chantal BEAUCHAMP : Formes et sens de la lutte sanitaire au XIX siècle : épidémies et endémies dans trois départements du Centre-Ouest (Indre, Indre-et-Loire et Loir-etCher). (Directeur J. P. PETER). 
François BESSON : À armes égales (une représentation de la violence en France et en Espagne au XII siècle. (Directeur : J. C. SCHMITT).

Jean BOUTIER: Construction et anatomie d'une noblesse urbaine: Florence à l'époque moderne (XVI ${ }^{\mathrm{e}}$-XVIII ${ }^{\mathrm{e}}$ siècle). (Directeur : M. AYMARD).

Brigitte BUETTNER : Les deux premiers manuscrits des "Clères femmes" de Boccace. Système de l'image dans un cycle profane destiné aux princes. (Directeur : J. C. SCHMITT).

Pierre DERRIDA : Le singulier. Guillaume d'Ockham. (Directeur : L. MARIN).

David, John FAUSETT: Amnioticon: histoire de l'utopie «australe». (Directeur: L. MARIN).

Margareth JAUDY CAMPOS DA SILVA PEREIRA: Rio de Janeiro: l'éphémère et la pérénnité. Histoire de la ville au XIX siècle. (Directeur : M. RONCAYOLO).

Hee-Young KWON : L'internationalisme devant la question nationale en U.R.S.S. Le parti bolchevik et la politique des nationalités du pouvoir soviétique à l'égard des BouriatesMongols et des Coréens (1917-1923). (Directeur : M. FERRO).

Philippe MARINVAL : Cueillette, agriculture et alimentation végétale de l'Epipaléolithique jusqu'au 2ème âge du fer en France méridionale. Apports palethnographiques de la carpologie.v (Directeur : J. GUILAINE).

Jean-Louis ORMIERES: Révolution et contre-révolution dans l'Ouest: le Haut-Anjou. (Directeur : F. FURET).

8 Vivi PERRAKI: "l'Expansion et la première crise pétrolière : lecture interdisciplinaire d'un journal économique lors d'un moment de discontinuité ». (Directeur : M. AYMARD).

Michel PRAT : Karl Korsch : de «Marxisme et philosophie » à la «crise du marxisme » (1923-1930). (Directeur : J. SCHERRER).

20 Athanassios STEFANIS : Le messager dans la tragédie grecque. (Directeur: P. VIDALNAQUET).

\section{Doctorats d'état}

21 Pierre ELLINGER: Recherches sur les «situations extrêmes" dans la mythologie d'Artemis et la pensée religieuse grecque. Autour de la légende nationale phocidienne et des récits de guerre d'anéantissement. (Directeur : J. P. VERNANT).

Jean-Michel GOGER: La politique routière en France de 1716 à 1815. (Directeur : J. C. PERROT).

3 Dominique LAVEDRINE de COURCELLES : L'« écriture » dans la pensée de la mort: les « goigs » en Catalogne de la fin du Moyen Age au début du XvIII siècle. Recherche sur un art poétique hagiographique, vu sous l'angle de l'histoire. (Directeur : L. MARIN).

Christine PHILI : La théorie des fonctions analytiques de Lagrange. Origine, formation, apogée, déclin et influence posthume d'une théorie politique. (Directeur : R. TATON). 